In: ISMÉRIO, Clarisse; PREVEDELLO, Carine (Orgs.). Nem tudo são rosas [recurso eletrônico]: refletindo os preconceitos, as lutas e conquistas femininas.

São Paulo: Vecher, 2021. Disponível em: <https://doi.org/10.47585/nemtudosaorosas>.

\title{
Por uma liberdade toda nossa: da opressão à emancipação das mulheres
}

Samanta Bergmam ${ }^{1}$ Fabiane Lazzaris ${ }^{2}$

doi.org/10.47585/nemtudosaorosas 11 1 Graduanda de Letras - Português e Literaturas de Língua Portuguesa da Universidade Federal do Pampa, http://lattes.cnpq.br/5570258734990619, e-mail: samantabergmam.aluno@unipampa.edu.br
2 Professora Adjunta do Curso de Licenciatura em Letras Línguas Adicionais - Inglês, Espanhol e Respectivas Literaturas da Universidade Federal do Pampa (UNIPAMPA), Doutora em Literaturas de Língua Inglesa pelo Programa de Pós-Graduação do Instituto de Letras da Universidade Federal do Rio Grande do Sul (UFRGS), coordenadora do projeto Grupo de Estudos Feministas (GEFEM)

e representante do Comitê Institucional Gênero e Sexualidade (PROEXT) da UNIPAMPA/Campus Bagé, http://lattes.cnpq.br/8975383125445316, e-mail: fabianelazzaris@unipampa.edu.br. 


\section{As amarras}

"Quem não se movimenta, não sente as correntes que o prendem" Rosa Luxemburgo

Sempre definidas por terceiros e por muitas vezes assumindo o papel de coadjuvantes na história (inclusive, em suas próprias vidas), mesmo quando não o eram, a trajetória das mulheres é marcada por tentativas constantes de libertação da subalternidade. Antes mesmo do termo 'feminismo' vir à tona ou de uma maior abertura de fala existir, a relação linguagem-mulher é estabelecida há milênios, ao carregar consigo juízos de valor muito bem definidos e pouco flexíveis. Em estudos referentes a esse fato, como a obra Problemas de Gênero: feminismo e subversão da identidade, escrita por Judith Butler e o artigo Uma análise discursiva das identificações de gênero, contido na obra Mulheres em discurso. Gênero, linguagem e ideologia, com autoria de M. Zoppi-Fontana e A.J. Ferrari, encontram-se discussões sobre como a língua exerce uma função social, sendo concretizada através da fala, no sentido de que cada escolha vocabular, quando realizada, dá-se pela ausência de uma outra, ou seja, dentre as inúmeras possibilidades terminológicas que estão à disposição, o indivíduo seleciona aquela que melhor traduz não só o que deseja expressar, como também a que melhor contempla seus posicionamentos internos e visões de mundo. Logo, entende-se que nenhuma combinação é neutra, pois sempre traz arraigada em si, questões relacionadas ao contexto sócio-histórico do falante que a emprega.

Com relação às chamadas ausências, ou silenciamentos, há uma tendência explícita de sobreposição de termos, na qual um é "dominante" e, na falta deste, é que pode surgir um outro. Assim, para deixar mais lúdica a explicação, podemos denominar esse segundo termo de "submisso", já que para existir, necessita sempre estar em oposição a um primeiro já existente. Sendo assim, levando em conta que, possivelmente, a linguagem forma a realidade, e que, "não existe nenhuma realidade social para uma dada sociedade fora de seu sistema particular de sexo-gênero", ou seja, fora das "categorias mutuamente exclusivas e exaustivas de masculino e feminino" (LAURETIS, 2019, p. 150), a categorização do ser feminino ficou historicamente relegada à oposição do hegemônico conceito de masculinidade.

Como exemplifica o trecho de Djamila Ribeiro (2014, p. 458), no qual evidencia que "[...] um dos grandes problemas em relação à definição da mulher, é que esta não é considerada um ser autônomo, não é definida em si, mas relativamente ao homem, em oposto ao que é ser homem". Diante das questões levantadas, é comprovado por inúmeros estudiosos que durante muito tempo (e até hoje), que as definições da palavra "mulher" ou se dão associadas à conceitos como "aquela que é fêmea", ao trazer nessa frase uma animalização explícita, ou ainda, "aquela que não é homem; que é do sexo feminino", propondo recortes bastante semicerrados, por usar como critérios: 1) a definição de homem como principal e primeira e, 2) partir de uma visão meramente biológica do que é o ser feminino.

Dentro dessa perspectiva, nota-se claramente o quanto a linguagem é um reflexo das dinâmicas sociais e como elas também são reforçadas para gerar um ciclo vicioso, um regime hierárquico até nos termos constituintes da língua. Como recorda Djamila Ribeiro (2014, p. 459), "na nossa língua, em muitos livros, utiliza-se a palavra homem para designar a humanidade. Se num grupo de várias mulheres estiver presente um homem, a flexão de gênero para designar essas pessoas será no masculino.", e ainda comenta que isso não só traz impactos individuais, mas também coletivos, pois a partir da definição de terceiros sobre a palavra e o ser 'mulher', é que implicitamente são definidos também, os conceitos associados à essa nomenclatura, como a performatividade do feminino, da estética, do comportamento e do papel social que deve ser desempenhado.

Conforme afirma Judith Butler (2019, p.213 - 214),

Nesse sentido, um gênero não é de forma alguma uma identidade estável do qual diferentes ações acontecem, nem seu lugar de agência; mas uma identidade tenuamente constituída no tempo identidade instituída por meio de uma repetição estilizada de certos atos. [...] uma identidade construída, uma performance em que as pessoas comuns, incluindo os próprios atores sociais que as executam, passam a acreditar e performar um modelo de crenças. 
Portanto, a formação de determinadas crenças relacionadas aos gêneros se dará a partir da repetição insistente de atos ilocucionários como "lugar de mulher é na cozinha e lavando louça", "a mulher tem de ser bela, recatada e do lar", ou "meninos vestem azul e meninas vestem rosa". A linguagem, os gestos e os signos são o que constitui uma simbologia social e, dessa forma, agentes sociais formam uma determinada realidade por meio da linguagem. (BUTLER, 2019, p. 213).

Em continuidade, tais reforçadores estão presentes nas mais distintas instâncias de influência cultural, como a Igreja, em seu caráter de instituição social. Não cabe nesta passagem adentrar à credos e crenças particulares, senão apenas no âmbito descritivo de algumas passagens. Dessa forma, é indiscutível a ordem cronológica empregada no livro de Gênesis, na qual primeiro foi criado Adão, e a partir da costela dele, só depois, formou-se $\mathrm{Eva}^{3}$, tal qual vimos acima, sobre primordialmente existir e conter, maior importância e amplitude na palavra "homem", do que na palavra "mulher", que depende desta primeira para depois surgir. Em outros trechos, observam-se constantes orientações sobre como a mulher deveria agir perante a sociedade, ao seu marido e em relação às suas vestimentas, prezando sempre manter em si um "[...] espírito manso e quieto" ${ }^{4}$, bem como atitudes obedientes para com seu esposo ${ }^{5}$.

É de suma importância ressaltar que qualquer ação e processo em favor da permanência desse imaginário coletivo e falocêntrico, resulta em consequências reais e em enormes atrasos históricos, que dificultam ainda mais a autonomia dos corpos femininos. É através da utilização da linguagem como método de dominação que os corpos femininos são simbolicamente e subjetivamente construídos. No entanto, sabemos hoje que conceitos de feminino ou feminilidade são puramente representações, "um posicionamento inserido no modelo fálico de desejo e significação, não se trata de uma qualidade ou propriedade da mulher." (LAURETIS, 2019, p. 143). E mesmo assim, ainda hoje nossos corpos são objetificados, somos sexualizadas precocemente e não temos plena autonomia sobre nosso próprio útero, para mencionar apenas alguns exemplos.

No entanto, em vista de que são os falantes que constituem a língua e são capazes de modificála sob suas demandas, pode surgir o seguinte questionamento: Então, onde estavam as mulheres para exigirem seu lugar nessa construção, frente à comunidade letrada? Pois bem, a questão não está em "onde", já que elas por sua vez, estiveram ali, vivendo na mesma época em que os homens também o faziam. As perguntas que deveriam ser fomentadas, porém, seriam: Ao que elas foram submetidas, a ponto de sequer serem ouvidas ou, ainda, de não encontrarem a sua própria voz? Que guilhões as impediram e ainda as impedem? E avançando mais, é plausível de se perguntar: Teríamos plena noção das amarras que nos diminuem, ainda hoje?

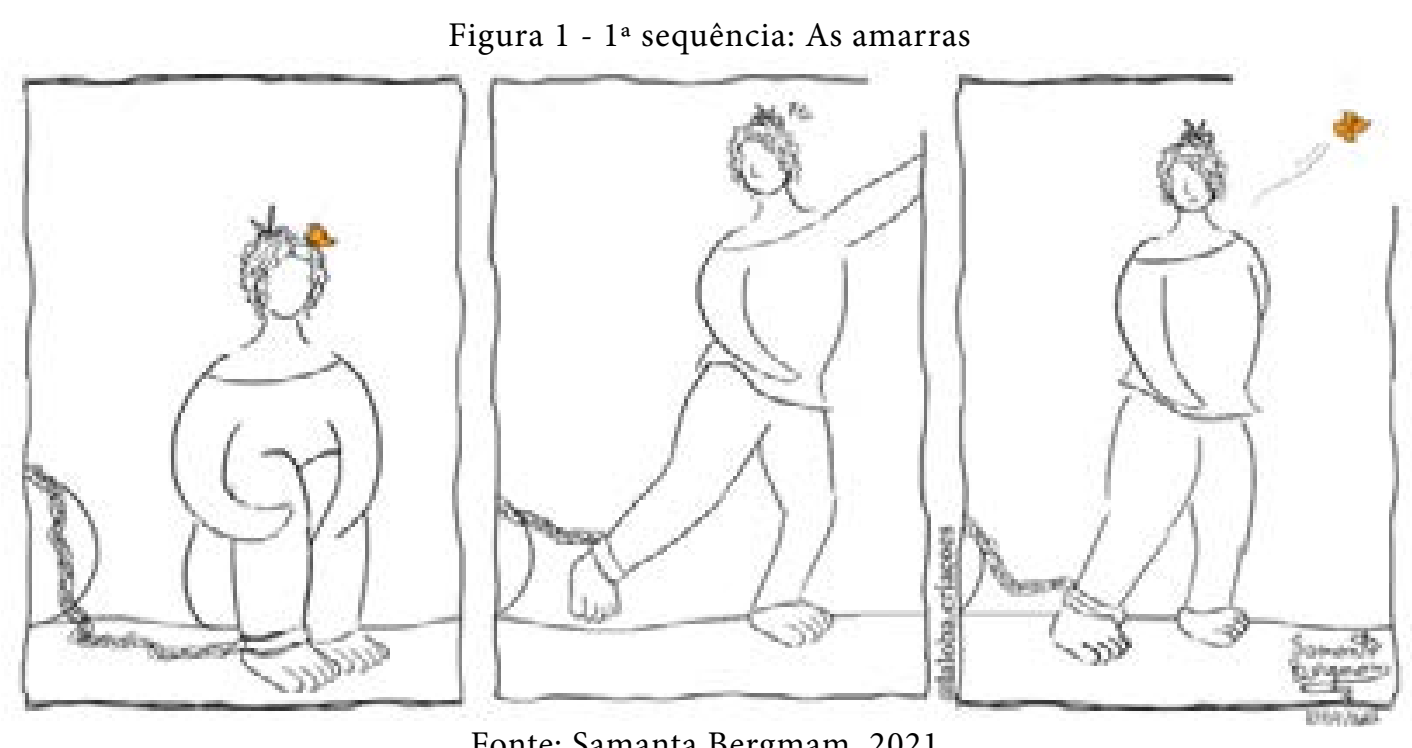

Fonte: Samanta Bergmam, 2021.

3 Gênesis 2:18-25. In: Bíblia do Pregador Pentecostal, SP: Sociedade Bíblica do Brasil, 2016.

4 I Pedro 3:4. In: Bíblia do Pregador Pentecostal, SP: Sociedade Bíblica do Brasil, 2016.

5 I Pedro 3:5-6. In: Bíblia do Pregador Pentecostal, SP: Sociedade Bíblica do Brasil, 2016. 


\section{A revolução}

"Não se nasce mulher; torna-se mulher" Simone de Beauvoir

Em Um Teto Todo Seu (1929), Virginia Woolf explica em que medida a posição que a mulher ocupa na sociedade do início do século XX, acarreta dificuldades para a expressão livre de seu pensamento e para a produção da escrita criativa feminina, livre de sujeição. Para exemplificar seu argumento feminista, Woolf imagina a existência de uma hipotética irmã de Shakespeare chamada Judith, que, assim como o irmão, era dotada de capacidade intelectual e talento artístico. No entanto, enquanto o irmão era enviado à escola e aprendia latim, a irmã aprendia a remendar roupas e cozinhar. Talvez se arriscasse a rabiscar algumas páginas, às escondidas, para não ser repreendida pelos pais. Enquanto o irmão se aventurava em Londres, ela, por sua vez, era preparada para ser noiva. Então, Judith foge para Londres, tenta trabalhar no teatro, mas o teatro não era coisa para uma mulher respeitável na época (na verdade, as mulheres não podiam atuar na Inglaterra Renascentista). Por fim, engravida e, impossibilitada de alcançar seu potencial intelectual e artístico, tira a própria vida em uma noite de inverno, e, portanto, nunca teria a oportunidade de se tornar uma brilhante dramaturga, como seu suposto irmão.

Assim, Woolf, através de um dos ensaios feministas mais importantes da história da literatura apresenta uma resposta possível à pergunta: “onde estariam as mulheres para lutar por seus direitos?" Por isso, vale ressaltar aqui, que a linguagem e a educação podem funcionar tanto como instrumentos de perpetuação de poder, mantendo o status quo e bloqueando o acesso de determinados grupos às instâncias de ascensão social, quanto como instrumento de subversão de elementos hegemônicos geralmente através de ressignificações simbólicas.

No ensaio icônico, Woolf discorre sobre a importância da emancipação financeira das mulheres, concluindo que para uma mulher conseguir escrever ficção e ser prestigiada, ela não pode ter de prestar contas a ninguém, daí a importância de toda mulher ter um "teto todo seu". Estamos lidando aqui com a primeira onda revolucionária feminista: as mulheres exigem direitos iguais de cidadania, direito à educação, direito a propriedade e posse de bens, ao divórcio e, acima de tudo, o direito ao voto. Não suficientemente alertas às amarras do capitalismo enquanto modo de produção patriarcal, as mulheres clamam por sua inserção na sociedade do acúmulo.

Em A Origem da Família, da Propriedade Privada e do Estado (1884), Friedrich Engels descreve que o desenvolvimento do conceito de propriedade privada é a "grande derrota histórica do sexo feminino", uma vez que, instituída a propriedade privada, os homens buscam garanti-la para eles e seus herdeiros através da manutenção da família monogâmica, o que envolve em grande medida, o domínio total sobre o útero da mulher

Controlando a sexualidade das mulheres com a exigência da virgindade pré-nupcial e a determinação do duplo padrão de julgamento sexual do casamento, os homens garantiram a legitimidade da prole, assegurando, assim, seu direito à propriedade. (LERNER, 2019, p. 49).

Ou seja, a família monogâmica patriarcal passa a ser uma unidade econômica na qual o trabalho doméstico da mulher se tornou um serviço não remunerado, logicamente, à serviço do marido ou pai. Sendo assim, as mulheres são relegadas à esfera doméstica e retiradas de toda a participação na produção social.

O sufrágio feminista, com suas demandas de inserção social, ao mesmo tempo que questiona o patriarcado e as relações de poder, serve de ferramenta de manutenção dessas mesmas relações na medida em que solicita a inserção de direitos em um sistema que não contempla as mulheres. O que esperar da inserção das mulheres em um modelo social e econômico dominado por homens? Gerda Lerner em $A$ Criação do Patriarcado (1986), afirma que "Leva muito tempo para que as mulheres entendam que receber papéis 'iguais' não as tornará iguais enquanto o roteiro, os objetos de palco, o cenário e a direção ficarem estritamente a cargo dos homens." (LERNER, 2019, p. 38). 
Simone de Beauvoir (1975), em entrevista televisiva concedida, ressalta o seguinte ponto: "Nunca se esqueça que basta uma crise econômica, política ou religiosa para que os direitos das mulheres sejam questionados. Esses direitos não são permanentes. Você terá que manter-se vigilante durante toda a sua vida.. Um espaço que sempre é contestado, uma diversidade de vivências que constantemente precisa ser legitimada e uma quebra árdua de estereótipos, são o que mais marcam o longo caminho em direção a liberdade e a humanização dos corpos femininos.

Há quem afirme que já avançamos muito. São décadas de luta das mulheres! Estamos, possivelmente, na quarta onda feminista, ao traçar relações entre gênero, classe, raça e sexualidade, questionar as performances de gênero e exigir que respeitem nossos corpos, nossas regras. Mas, ainda assim, somos subjugadas, silenciadas, violadas. Teriam as mulheres uma natural propensão à servidão? A construção performativa do feminino servil, desenvolveu nas próprias mulheres uma espécie de altruísmo compulsório: como se independentemente de como fossem tratadas, deveriam estar dispostas a atender qualquer pedido, desejo ou ordem a qual eram submetidas. Tal repetição seriada tornou-se tão agressiva a ponto de, mesmo infelizes, com suas ressalvas ou até mesmo conscientes de sua condição, as mulheres continuavam (quiçá continuam) a suprir as demandas sociais, conjugais e maternas, acarretando em uma vivência (ou sobrevivência) incompleta e imposta. Desse modo, até os dias de hoje praticamente toda fala ação, gesto, estímulos visuais e sonoros ainda nos induzem a reafirmar tal comportamento social.

Em alguns casos mais extremos, esse padrão de acatamento e estadia é denominado Ciclo da Violência, termo criado em 1979 pela psicóloga Lenore Walker (FERNANDES, 2018), e que contempla três fases que agem como uma espécie de teia na qual muitas vezes, sem nem perceber, a mulher já está envolta e não consegue se desvencilhar. Seriam elas: 1) o aumento de tensão; 2) o ataque violento e 3) a calmaria ou a "lua de mel". A situação de submissão e subalternidade não é uma zona de conforto, como alguns podem equivocadamente compreender. Deve-se considerar a complexa teia de opressão pela qual as mulheres são submetidas há séculos.

Entende-se através do exemplo da teia, que um inseto, por mais forte e astuto que seja, raramente consegue se livrar de uma teia bem construída, pois mesmo que ele se debata e se esforce, a aranha vai lhe aprisionando ainda mais, sendo difícil sair ileso sem nenhuma ajuda. Imagine, então, uma teia construída há milênios com o objetivo de diminuir o feminino, uma relação opressiva de anos e um apagamento histórico de séculos, feito para silenciar toda e qualquer mulher! Alguns levantarão elucubrações sobre mulheres que se destacaram ao longo dos séculos: o que podemos dizer de Cleópatra, Joana D’arc, Boudica? Vale lembrar que a historiadora Gerda Lerner ressalta que "Não existe uma só sociedade conhecida na qual 'mulheres como grupo' tivessem poder de decisão sobre os homens ou definissem as regras de conduta sexual, ou mesmo controlassem as transações de casamento." (LERNER, 2019, p. 58). Ainda, torna-se relevante apontar que o feminismo sempre se preocupou com o debate estrutural, ou seja, "Não se trataria de afirmar experiências individuais, mas de entender como o lugar social ocupado por certos grupos restringe oportunidades" (RIBEIRO, 2019, p. 60) É preciso fazer o cruzamento das relações entre raça, gênero, classe e sexualidade para entender os dispositivos fundamentais de opressão dirigidos a determinados grupos.

Observar e admitir a realidade em que se vive é o primeiro passo para uma transformação maior, mesmo que depois, outras instâncias sejam fundamentais nessa luta, como a reivindicação por direitos, representatividade e respeito. Apesar de atitudes individuais provocarem algum tipo de libertação, é necessário que pensemos como grupo. A demanda das mulheres é coletiva, pois como afirma Audre Lorde "Não sou livre enquanto outra mulher for prisioneira, mesmo que as correntes dela sejam diferentes das minhas". O patriarcado não afeta todas as mulheres da mesma maneira. Privilégios de raça e classe amortecem parte da opressão que algumas mulheres vivem. Para outras, a inexistência dos mesmos privilégios é o que diferencia oportunidades e condições de vida. Em alguma medida o nosso locus social define a diferença entre viver e morrer. 


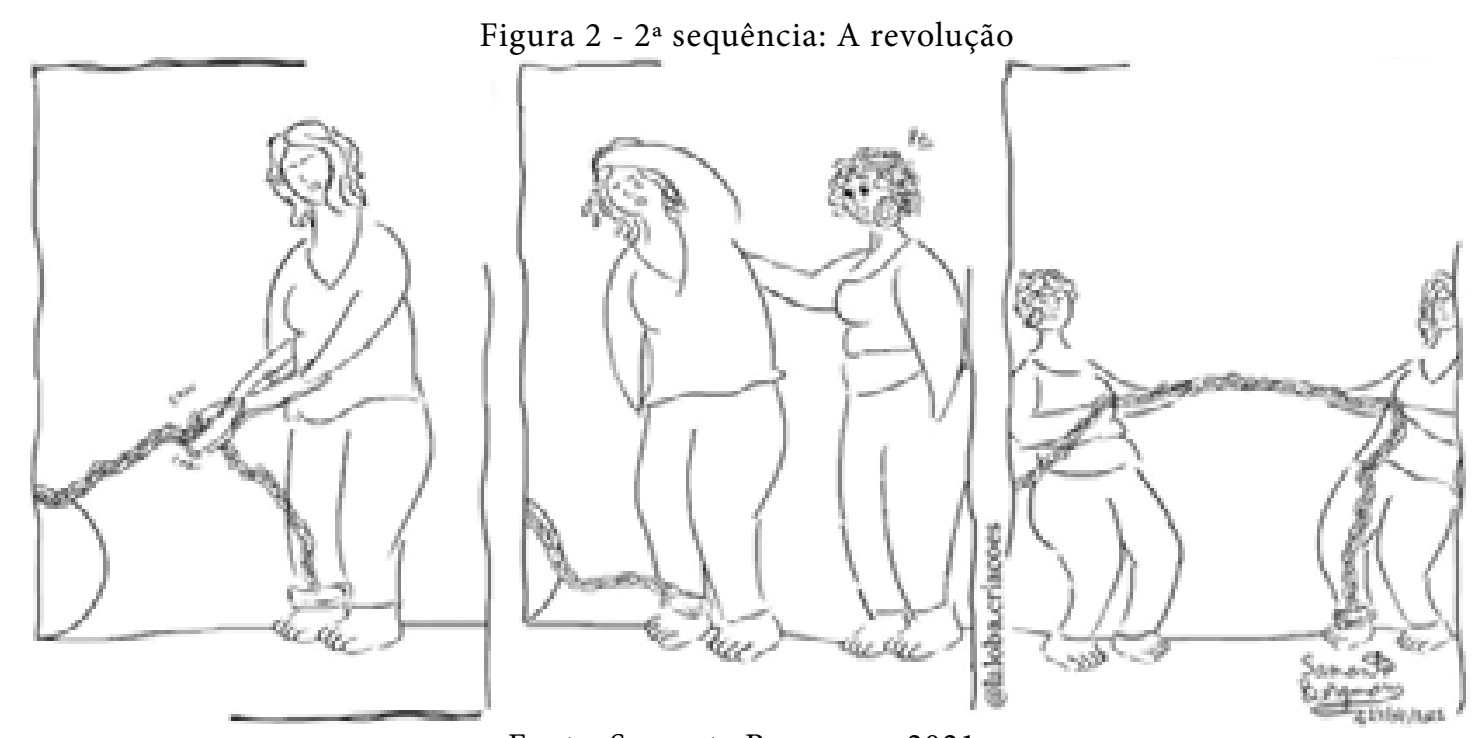

Fonte: Samanta Bergmam, 2021.

\section{A liberdade}

"Tranque as bibliotecas, se quiser; mas não há portões, nem fechaduras, nem cadeados com os quais você conseguirá trancar a liberdade do meu pensamento"

Virginia Woolf, Um Teto Todo Seu

O conhecimento é incendiário: a faísca de uma simples sinapse pode se alastrar para um esclarecimento gigante, um raciocínio crítico, uma autonomia de si mesma. Não à toa que o acesso a qualquer troca que possa vir a somar e agregar, está entre as primeiras coisas a serem detidas nos regimes totalitários ou em crises de poder, como já foi evidenciado por Beauvoir anteriormente. Ao utilizar a palavra "conhecimento", vale ressaltar que não pode nem deve ser incluído apenas a compreensão do conhecimento acadêmico, haja vista que as vivências e os saberes precisam ser entendidos como diversos entre si, sem acontecer qualquer sobreposição ou juízo de valor sobre eles: o conhecimento em si e sobre si, independente de como se manifeste, é emancipatório.

Sendo assim, é preciso reconhecer as pequenas resistências internas e diárias: a mãe que decide educar os filhos de uma maneira diferente de como foi criada, a senhora que costura e cozinha e a partir disso consegue pagar os estudos da filha, a moça que decide não ter filhos, as jovens que entrelaçam as mãos ao caminhar na rua, a mulher que decide voltar-se para o veganismo, o grupo de vizinhas que organiza uma horta comunitária, entre outros exemplos que têm seu lugar e fazem parte dessa vastidão de vivências. Todas essas ações e muitas mais têm igualmente seu lugar de (r)existência, não só pelo destino de suas vidas, mas também para a colaboração de um presente e de um futuro melhor para a vida de outras pessoas, para além de seus recortes e dos grupos que exercem maior atuação. Não obstante, é preciso perguntar: como nos libertaremos enquanto grupo? Até quando seremos subjugadas?

María Lugones, a partir da concepção de colonialidades de poder (2005) de Aníbal Quijano, propõe uma releitura da modernidade colonial capitalista e acrescenta uma nova leitura sobre gênero e raça, dentro da lógica da imposição colonial. Ou seja, a lógica opressora e colonizadora da modernidade colonial, determinaria também as relações de gênero, e, claro, raça. Desse modo, Lugones ainda afirma veementemente que, "a imposição colonial dos gêneros atravessa questões ecológicas, econômicas, governamentais, atravessa a relação com o mundo dos espíritos, o conhecimento, bem como as práticas diárias que nos ensinam ou a cuidar do mundo ou a destruí-lo." (LUGONES, 2019, p. 357). Sua resposta em relação às formas de resistir às imposições coloniais vigentes até hoje está na comunalidade. Lugones aponta para uma resposta coletiva na (re)produção da vida diária, na qual a liberdade virá, também, em forma de resistência coletiva.

Ninguém resiste à colonialidade dos gêneros sozinho. Somente é possível resistir a ela com o entendimento do mundo e com uma vivência que é compartilhada e consegue entender as próprias ações - garantindo certo reconhecimento. As comunidades, e não os indivíduos, possibilitam o fazer; as pessoas produzem junto das outras, nunca em isolamento. O boca a boca, a passagem de mão em mão das práticas vividas, dos valores, das crenças, ontologias, 
espaço-tempo e cosmologias constituem as pessoas. A produção da vida diária, na qual existimos, produz nossos Eus, à medida que nos provêm vestimentas, comida, economias e ecologias, gestos, ritmos, habitats e noções de espaço e tempo [...] esses caminhos não são apenas diferentes: eles afirmam um ideal da vida acima do lucro, de um comunalismo acima do individualismo [...] (LUGONES, 2019, p. 372 - 373).

O conhecimento e o acolhimento, em seus significados mais amplos, podem fortalecer a luta por liberdade, para algo muito mais profundo do que se pode imaginar: para uma autodefinição de si próprias, no plural. Não apenas para uma, nem para um recorte do feminino, mas para toda sua diversidade de vivências e experiências, sem amarras, grilhões ou podas, que tendem a ser feitas muito cedo, como se para evitar a descoberta de uma força interior que, desde sempre, esteve ali. A construção de uma linguagem mais plural, compreensiva e respeitosa depende da liberdade e, a liberdade por sua vez, depende da potência que há em nossas vozes, quando são ressoadas em conjunto, pois independente do que digam ou tentem nos fazer acreditar, essa potência existe e está pronta para revolucionar.

Figura 3 - 3a sequência: A liberdade
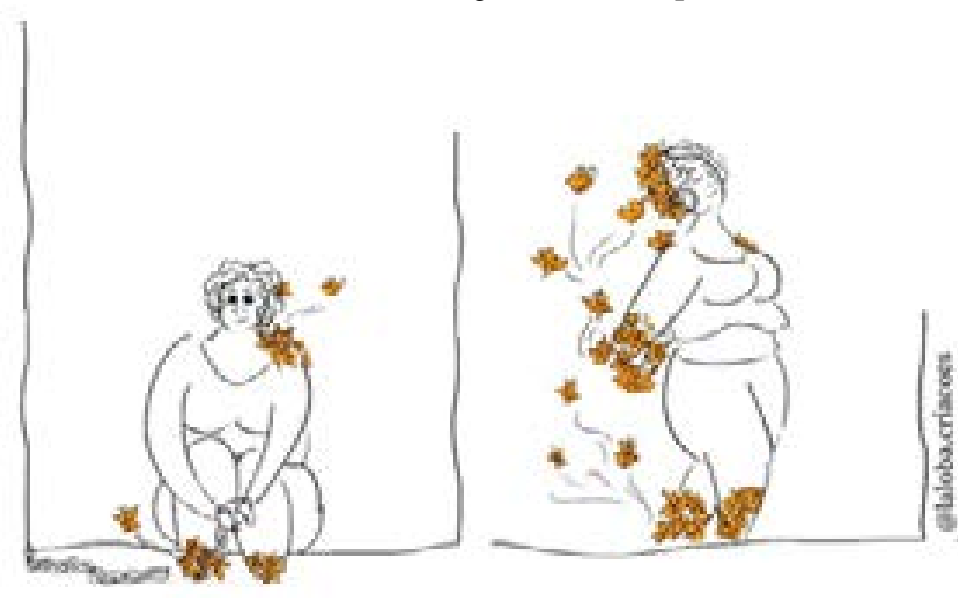

$*$
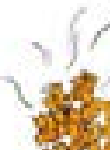

案

Fonte: Samanta Bergmam, 2021.

\section{Referências}

BEAUVOIR, S. de. (1975). Por que sou feminista. Entrevista de Simone de Beauvoir concedida para o programa "Questionnaire", por Jean-Louis Servan-Schreiber. Disponível em: $<$ http://prceu.usp.br/uspdiversidade/genero/simone-de-beauvoir-porque-sou-feminista-1975/>. Acesso em: 3 jun. 2021.

BÍBLIA do Pregador Pentecostal, SP: Sociedade Bíblica do Brasil, 2016.

BUTLER, Judith. Atos performáticos e a formação dos gêneros: um ensaio sobre fenomenologia e teoria feminista. In: HOLLANDA, Heloísa Buarque de. (Org.) Pensamento Feminista: Conceitos Fundamentais. Rio de Janeiro: Bazar do Tempo, 2019. p. 213 - 234.

BUTLER, Judith. Problemas de gênero: feminismo e subversão da identidade. Tradução de Renato Aguiar. Rio de Janeiro: Civilização Brasileira, 2003.

ENGELS, Friedrich. A Origem da Família, da Propriedade Privada e do Estado. Boitempo, 2019. 196 p.

FERNANDES, Tainah. O que é, como enfrentar e como sair do ciclo da violência. Agência Patrícia Galvão. 10 dez. 2018. Disponível em: <https://agenciapatriciagalvao.org.br/destaques/ o-que-e-como-enfrentar-e-como-sair-do-ciclo-da-violencia/>. Acesso em: 7 abr. 2021.

LAURETIS, Teresa de. A tecnologia de Gênero. In: HOLLANDA, Heloísa Buarque de. (Org.) Pensamento Feminista: Conceitos Fundamentais. Rio de Janeiro: Bazar do Tempo, 2019. p. 121 - 156. 
LERNER, Gerda. A Criação do Patriarcado: história da opressão das mulheres pelos homens. Tradução de Luiza Sellera. São Paulo: Cultrix, 2019. 375 p.

LUGONES, María. Rumo a um Feminismo Decolonial. In: HOLlANDA, Heloísa Buarque de. (Org.) Pensamento Feminista: Conceitos Fundamentais. Rio de Janeiro: Bazar do Tempo, 2019. p. 357 - 378.

RIBEIRO, Djamila. Linguagem, gênero e filosofia: qual o caminho criado para as mulheres? Uma abordagem Wittgensteiniana. Belo Horizonte, v.5 - n.9, p.453-463. $1^{\circ}$ sem. 2014. ISSN: 2177-6342. Disponível em: <http://www.periodicos.pucminas.br/index.php/SapereAude/article/view/7674> Acesso em: 20 fev. 2021

RIBEIRO, Djamila. Lugar de Fala. São Paulo: Pólen, 2019. 112 p.

WOOLF, Virginia. Um Teto Todo Seu. Tradução de Bia Nunes de Sousa e Glauco Mattoso; [capa: Andrea Vilela], 1a ed. São Paulo: Tordesilhas, 2014.

ZOPPI-FONTANA, M; FERRARI, A.J. Uma análise discursiva das identificações de gênero. In ZOPPI-FONTANA; FERRARI, A.J. (Org.) Mulheres em discurso. Gênero, linguagem e ideologia. $1^{\mathrm{a}}$ ed. Campinas: Pontes, 2017. v. 1. 276 p. 